Stefano ZoIA

\title{
First citation of Macrocoma splendens for La Gomera, Canary Islands (Coleoptera Chrysomelidae Eumolpinae)
}

\begin{abstract}
Riassunto: Prima segnalazione di Macrocoma splendens per La Gomera, Isole Canarie (Coleoptera Chrysomelidae Eumolpinae). Macrocoma splendens Lindberg, 1950 viene segnalata per la prima volta per La Gomera (Isole Canarie) e gli esemplari esaminati sono comparati con quelli provenienti da La Palma e Tenerife. È questa la prima segnalazione di una Macrocoma per La Gomera.
\end{abstract}

\begin{abstract}
Macrocoma splendens Lindberg, 1950, is reported for the first time for La Gomera (Canary Islands) and examined specimens are compared with specimens collected at La Palma and Tenerife. This is the first citation of a Macrocoma species for La Gomera.
\end{abstract}

Key words: Macrocoma, Canary Islands, La Gomera, new data.

\section{INTRODUCTION}

In a review regarding Macrocoma of the Canary Islands, Zoia (2017) reported that there was no knowledge establishing a connection with La Gomera. I recently had the opportunity to examine a small series of a Macrocoma species from La Gomera that can be referred to M. splendens Lindberg, 1950, previously known from La Palma and Tenerife (Zoia, 2017: 80-81 and Figs 40-46 and 68).

\section{Macrocoma splendens Lindberg, 1950}

EXAMINED MATERIAL. Canary Is., La Gomera, Alto de Garajonay, 1350-1450 m, 20-24.6.2005, M. \& J.

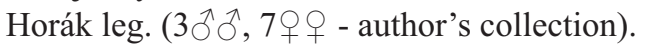

Notes. Examined specimens are quite uniform in their habitus and coloration; females are somewhat bigger and stouter than males, otherwise hardly distinguishable in their exoskeletal characteristics. They fully match the characteristics reported in the key of Zoia, 2017: 77. Legs reddish, antennae reddish with antennomeres 7 th11th partially darkened distally. Dorsum metallic bronze with a dense punctation made of small but impressed punctures. Elytra with dense pubescence, partly arranged in nine more or less evident longitudinal rows of longer and erected setae.

Aedeagus as in Figs 1-2, somewhat more briefly rounded at apex in dorsal view than in specimens from both Tenerife and La Palma (Zoia, 2017: figs 42 and 45 ) and somewhat stouter in lateral view (Zoia, 2017: figs 43 and 46).

Spermatheca as in Fig. 3, with both spermathecal gland and ductus somewhat longer than in the specimen from Tenerife portrayed in Zoia, 2017: fig. 68; spermathecal gland ending in a small ovoidal widening.

From my point of view, said differences, although distinguishing the specimens from La Gomera, do not call for a taxonomic separation among populations of different islands.

*Stefano Zoia, Via Ponte Nuovo, 109/4, 20128 Milan, Italy. E-mail stefano.zoia@chrysomelidae.it 


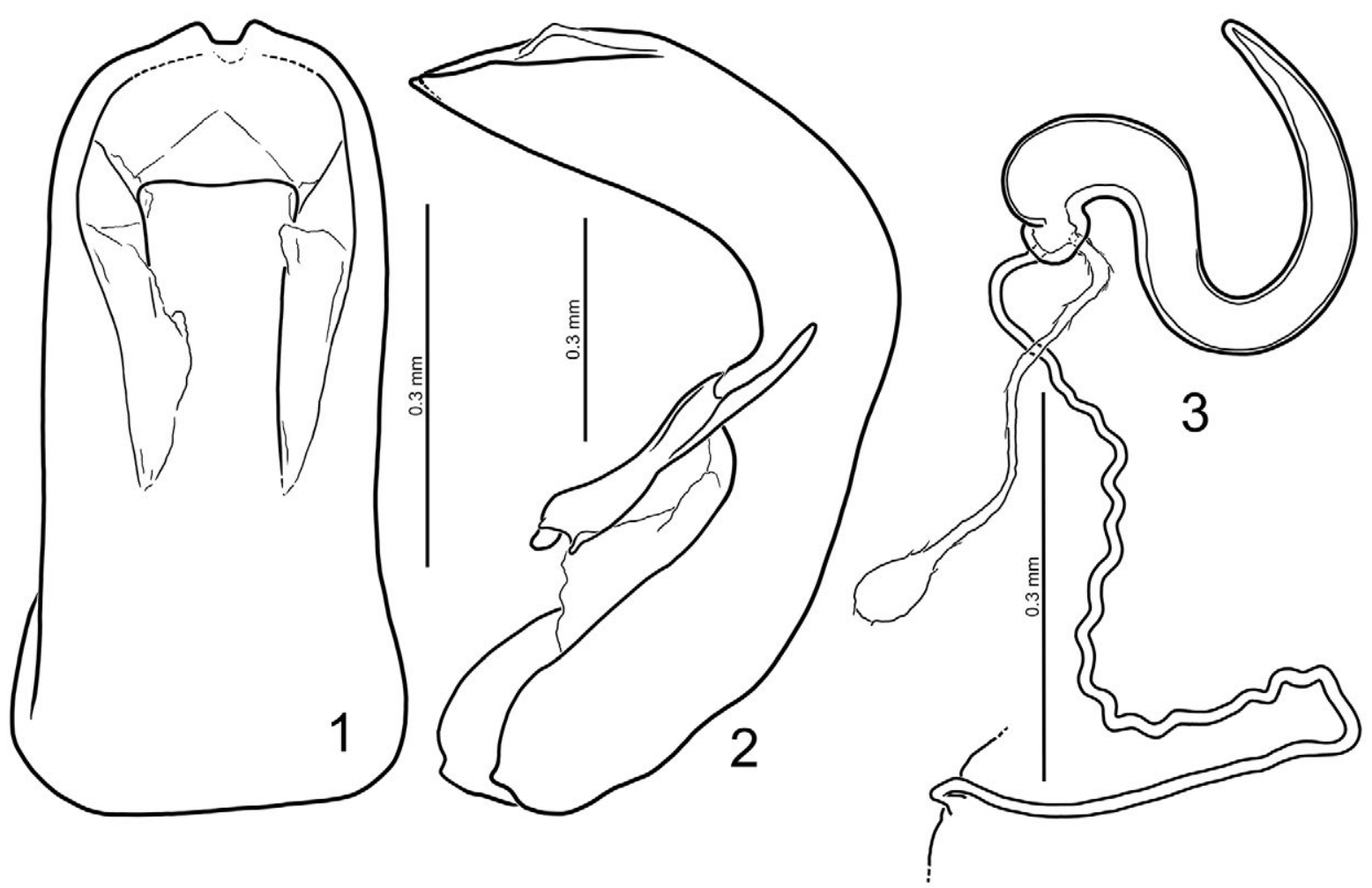

Figs 1-3. Macrocoma splendens (La Gomera, Alto de Garajonay, 1350-1450 m): 1 - aedeagus, dorsal view; 2 - idem, lateral view; 3 - spermatheca.

\section{REFERENCES}

ZoIA S., 2017 - The Macrocoma Chapuis from the Canary Islands, with description of a new species (Coleoptera Chrysomelidae Eumolpinae). Bollettino della Società Entomologica Italiana, 149 (2): 75-92. 